\title{
DIFERENCIAS EN EL TRÁMITE DE NOTIFICACIÓN AL DEMANDADO DEL AUTO ADMISORIO DE LA DEMANDA EN LOS PROCESOS CIVILES Y ORDINARIOS LABORALES
}

\author{
Ana María Rodríguez Cáceres \\ Abogada, Esp. Derecho Procesal, Universidad Santo Tomás-Bucaramanga (Col). \\ E-mail:annmary.a@hotmail.com \\ Lorena Liliana Cruz Quiñonez. \\ Abogada, Esp. Derecho Procesal, Universidad Santo Tomás- Bucaramanga (Col). \\ E-mail: lily1898@hotmail.com \\ Jenny Catalina Monsalve García \\ Abogada, Esp. Derecho Procesal, Universidad Santo Tomás- Bucaramanga (Col). \\ E-mail: jennyc_monsalve@hotmail.com
}

\begin{abstract}
Resumen
El siguiente texto pretende hacer un acercamiento a los procesos civiles y ordinarios laborales a partir de la notificación que se hace al demandado en el auto admisorio de la demanda. El tema de la notificación es visto desde las ópticas convencionales que la justifican a partir de la idea del debido proceso, la transparencia del mismo, el derecho a la defensa, el conocimiento de las decisiones judiciales y la comunicación de las partes. Se describen los casos en que debe hacerse uso de un curador ad litem y las implicaciones que esto conlleva en materia procesal pues entran en colisión ciertos principios de orden constitucional. Finalmente se expone las diferencias entre los trámites en materia civil y en materia laboral a partir de las garantías procesales y advierte sobre la importancia de unificar ambos procesos.
\end{abstract}

\section{Palabras clave}

Procesos civiles y laborales, notificación, curador ad litem, principios procesales, principios constitucionales y garantías procesales.

\begin{abstract}
The following text pretends to make an approach to the notification of the admission of a legal process to the defendant within civil and ordinary labor law processes. The notification process is seen from many perspectives that justify the idea of the legal process, the transparency of it, the right to self-defense, the right to know the judicial decision and the communication between the opposite sides of the process. The author describes the cases in which the ad-litem curator must be used and its implication that this process figure drives to in the process, since certain constitutional principles collides with one another. Finally, the differences between the steps to designate a ad-litem curator in civil and labor law are exposed considering the procedural guarantees and warns about the importance to unify both processes.
\end{abstract}

\section{Key Words}

Civil and labor law processes, notification, ad litem curator, process principles, constitutional principles, and procedural guarantees 

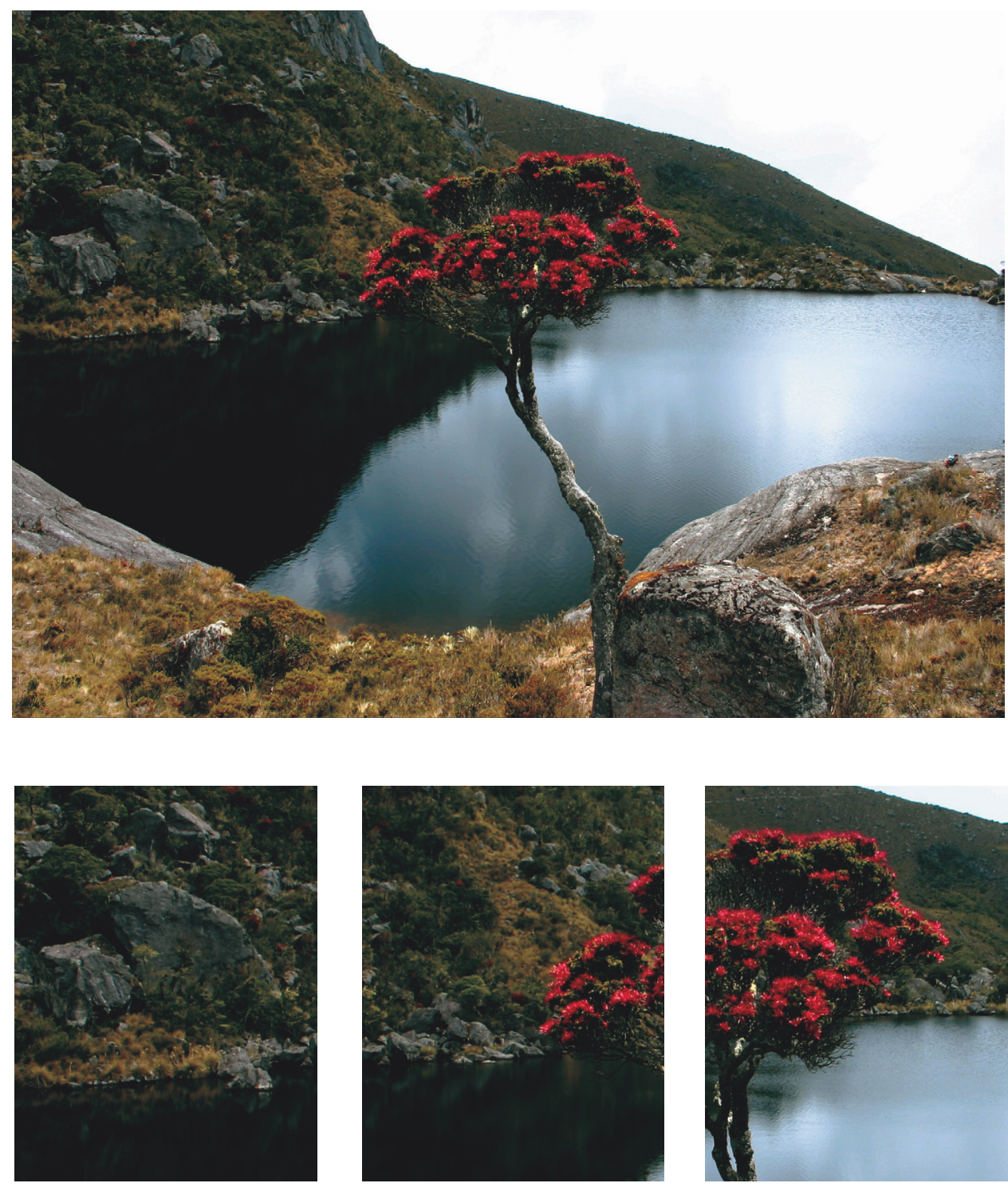

El Siete Cueros en una de las "Lagunas de Páez" 


\section{DIFERENCIAS EN EL TRÁMITE DE NOTIFICACIÓN AL DEMANDADO DEL AUTO ADMISORIO DE LA DEMANDA EN LOS PROCESOS CIVILES Y ORDINARIOS LABORALES*}

Ana María Rodríguez Cáceres Lorena Liliana Cruz Quiñonez Jenny Catalina Monsalve García

\section{Introducción}

Dentro del entramado de las dinámicas jurídicas el trámite de los procesos judiciales y particularmente la notificación reviste trascendental importancia, ya que posibilita la salvaguarda de muchas de las garantías procesales que deben tenerse en cuenta en dichos procedimientos, siendo que ésta, tiene por fundamento el derecho que ostentan las partes o los interesados en un proceso de conocer las providencias que en estos se profieren, sin embargo, pese a la relevancia que amerita el tema se encuentran disposiciones judiciales, e incluso vacíos jurídicos que trasgreden las garantías procesales de los intervinientes en una litis, tal como se presenta en la normatividad vigente en lo que hace a los procesos ordinarios laborales, y que queda aun en mayor evidencia al realizar un ejercicio comparativo con las disposiciones que rigen la misma materia en el marco del procedimiento civil.

Así, el presente artículo pretende poner de manifiesto la flagrante vulneración a las garantías procesales que emerge a partir de la normatividad vigente en el Código Procesal del Trabajo y de la Seguridad Social en cuanto a la notificación al demandado en un proceso ordinario laboral del auto admisorio de la demanda, partiendo de un análisis comparativo con la legislación procesal civil, a fin de plantear posibles salidas

\footnotetext{
* El artículo reflexiona sobre el tema de trámite de notificación del auto admisorio, al demandado, en los procesos civiles y laborales. El ejercicio se desarrolla en el marco de la asignatura de Metodología de la Investigación (Asesor Docente Javier Díaz Díaz) de la Especialización en Derecho Procesal Cohorte III - Universidad Santo Tomás-Seccional Bucaramanga.
} 
a múltiples inconvenientes. Tal y como se expondrá, es evidente que al sobreponer la categoría de los derechos que eventualmente se vulneran con el trámite en cuestión, sobre la normativa vigente que, pese a pretender salvaguardar otros tantos derechos, trasgrede flagrantemente las garantías procesales que deben ser tenidas en cuenta en todo trámite procesal, termina por perjudicarse altamente los intereses esenciales de la justicia, y aún en mayor medida los intereses de quienes se ven involucrados en procesos judiciales, con lo cual se muestra como altamente necesaria una reforma a la legislación que regula el trámite de los procesos ordinarios laborales.

En este orden de ideas, el problema en cuestión busca indagar por las razones que explican las diferencias en los trámites de notificación al demandado del auto admisorio de la demanda en el marco de los procesos civiles y laborales. Sin embargo, antes de adentrarse formalmente el asunto y a fin de lograr mayor comprensión acerca del tema se hace necesario analizar los principales conceptos relacionados con el cuestionamiento que se plantea.

\section{Aproximaciones conceptuales}

El primero y más básico de los conceptos a utilizar será el de derecho procesal, entendido éste como aquel que contiene los principios y normas que han de regir el trámite de los asuntos ante la administración de justicia (Cabanellas, 2003, 123); sin embargo, hoy en día su definición implica un carácter más general en cuanto también se extiende a los particulares al abarcar, no solo el estudio básico y concreto de los procedimientos, sino además el examen de la actividad de todos los órganos de la administración pública. Partiendo de éste concepto surgen otros más que se ven inmersos dentro de la función administrativa y judicial del Estado, tales como los principios de igualdad, defensa, moralidad, economía, celeridad, eficacia, imparcialidad, publicidad e incuso el debido proceso, que además cuentan con respaldo constitucional, y que se convierten en eje fundamental para el desarrollo del presente trabajo. Así, el principio de igualdad puede ser entendido como la ausencia de desequilibrios entre las partes en el desarrollo de los procesos judiciales; el de economía que implica la obtención de resultados con el empleo del mínimo de actividad procesal, naturalmente sin violación al derecho fundamental al debido proceso, que a su vez puede ser entendido como la suma de garantías que protegen a quienes se someten a cualquier tipo de proceso y que les aseguran una recta y cumplida administración de justicia, de donde se deriva el derecho a la defensa que a su vez implica el derecho de acudir ante la jurisdicción a plantear oposiciones y a controvertir pruebas, y sin dejar de lado el principio de publicidad que también se convierte en una garantía al presentarse como una garantía de exclusión de la arbitrariedad en el trámite de los procesos al implicar cierto grado de notoriedad pública (Villamil, 1999).

Del principio de publicidad se deriva otro concepto importante que en sí permite concretar la publicidad de las decisiones judiciales, éste es el de notificación, pues 
como ya se ha enunciado, éstas deben ser comunicadas a las partes o interesados en la litis para que una vez conocidas puedan ser impugnadas, aclaradas, complementadas, o simplemente se dé a conocer su contenido, para lo cual el legislador estableció diversas clases de notificaciones siendo la principal la notificación personal, que busca enterar de manera directa e inmediata a los sujetos de derecho interesados, de las determinaciones proferidas dentro del proceso (ibídem).

Una vez se ha surtido el trámite de notificaciones sin haberse logrado la comparecencia del demandado al proceso, la legislación procesal tanto civil como laboral, ha establecido como mecanismo para garantizar el derecho a la defensa la designación de curador ad litem, quien se encarga de asumir la defensa de los intereses del encartado buscando que el trámite procesal se adelante sin lugar a dilaciones y con plena garantía de los derechos del demandado, siendo precisamente éste el eje fundamental del presente asunto.

En torno al tema - los trámites de notificación al demandado- existen instrumentos analíticos que a nivel internacional permiten entrever la importancia de esta reflexión; por ejemplo el artículo 14 de la Carta Internacional de Derechos Humanos o Pacto Internacional de Derechos Civiles y Políticos, dispone que todas las personas tendrán derecho a ser oídas públicamente y con las debidas garantías ante un tribunal competente, así como también señala el derecho que les asiste para ser informadas sin demora de la naturaleza y causas de la acusación que se les formula. En el mismo sentido se refiere el Pacto de San José de Costa Rica o Convención Americana sobre Derechos Humanos, que en su artículo octavo establece que toda persona tiene derecho a obtener comunicación previa y detallada de la acusación formulada en su contra. A nivel nacional, la Constitución Política de 1991, consagra en el artículo 29, que "toda persona tiene derecho a un debido proceso público y sin dilaciones injustificadas; a presentar pruebas y a controvertir las que se alleguen en su contra, a impugnar la sentencia condenatoria, y a no ser juzgado dos veces por el mismo hecho." Esto evidencia la importancia que reviste la comunicación que debe hacerse de las providencias judiciales en aras de garantizar a las partes e interesados derechos fundamentales tales como el acceso a la justicia, la defensa y el debido proceso, derechos de carácter constitucional que incluso cuentan con protección por parte de instrumentos internacionales. Sin embargo, la legislación colombiana cuenta con vacíos normativos, e incluso con disposiciones, que van en contra de la garantía que debe darse a estos derechos, muy especialmente a lo que hace referencia al tema de las notificaciones en los procesos ordinarios laborales.

Ya habiendo dejado claro algunos de los referentes teóricos dentro de problemática planteada, es necesario comenzar a conocer el contenido de los procesos ordinarios laborales, ya que es allí donde se presentan las dificultades en cuanto a la notificación del auto admisorio de la demanda, que a diferencia de otras legislaciones procesales, puede violar garantías a los demandados.

Al respecto, es de público conocimiento que es a través del procedimiento ordinario laboral -establecido en los artículos 70 y siguientes del Código Procesal 
del Trabajo y de la Seguridad Social (en adelante C.P.T.S.S)- como se tramita toda controversia laboral, cualquiera que sea, que no tenga señalado un trámite especial previsto en la ley. Dentro de dichos trámites especiales están el fuero circunstancial, la cancelación de la inscripción en el registro sindical, la disolución y la liquidación de asociaciones profesionales y suspensión y cancelación de personarías jurídicas, así, cualquier otro asunto deberá tramitarse a través del proceso ordinario laboral.

El artículo 41 del C.P.T.S.S. establece en el numeral primero del literal A, que la notificación al demandado "del auto admisorio de la demanda y, en general, la que tenga por objeto hacerle saber la primera diligencia que se dicte" debe hacerse personalmente; sin embargo, como es lógico, pueden presentarse casos en que se haga imposible la notificación personal, por lo cual, teniendo en cuenta que lo que se pretende es garantizar el debido proceso y el derecho de contradicción impidiendo el adelantamiento de procesos secretos en donde se vulneren los derechos de los particulares, la notificación personal también se puede ejecutar por medio de curador ad litem (Isaza, 1995, 479) quien se encarga de asumir la defensa de los intereses del encartado, propendiendo así además para que el trámite procesal se adelante sin lugar a dilaciones y con plena garantía de los derechos del demandado.

El artículo 29 del C.P.T.S.S. establece respecto del nombramiento del curador ad litem y del emplazamiento al demandado:

"Cuando el demandante manifieste bajo juramento, que se considera prestado con la presentación de la demanda, que ignora el domicilio del demandado, el juez procederá a nombrarle curador para litis con quien se continuará el proceso y ordenará el emplazamiento por edicto, con la advertencia de habérsele nombrado curador...

...El emplazamiento se efectuará en la forma prevista en el inciso segundo del artículo 318 del Código de Procedimiento Civil y no se dictará sentencia mientras no se haya cumplido...
...Cuando el demandado no es hallado o se impide la notificación, también se aplicará lo dispuesto en los incisos anteriores, previo cumplimiento de lo establecido en los numerales 1y 2 del artículo 320 del Código de Procedimiento Civil. En el aviso se informará al demandado que debe concurrir al juzgado dentro de los diez (10) días siguientes al de su fijación para notificarle el auto admisorio de la demanda y que si no comparece se le designará un curador para la litis"

Se encuentra entonces que el nombramiento de curador ad litem procede en dos eventos: cuando se ignora el domicilio del demandado y cuando éste no es hallado o se impide su notificación, en donde, en ambos casos, se cita al demandado mediante edicto emplazatorio.

En el primer caso, es decir, cuando se desconoce el domicilio del demandado, para que proceda el emplazamiento que dispone la norma, el demandante debe manifestar bajo juramento que ignora el domicilio del demandado, juramento éste que se considera prestado con la sola presentación de la demanda; una vez ocurre 
esto se nombra curador para la litis y se ordena el emplazamiento correspondiente en donde además debe advertirse el nombramiento de curador que ya se ha realizado.

Aquí hay que hacer claridad también en la figura del emplazamiento, como otra forma de convocatoria que por orden de un Juez se hace a determinada persona para que comparezca dentro del término que se le concede por ley a defenderse de los cargos que se le hacen, oponerse a la demanda (Rodríguez, 1980, 95), y en general, a ejercer el derecho a la defensa que le asiste, en el caso de la notificación del auto admisorio de la demanda, sólo en aquellos casos en que no ha sido posible surtirse la notificación personal establecida por la norma procesal.

El emplazamiento, como lo dispone el artículo 29 del C.P.T.S.S. trascrito antes, se efectúa de acuerdo a lo establecido en el inciso segundo del artículo 318 del C.P.C., subrogado por el artículo 30 de la ley 794 de 2003, es decir, mediante la inclusión del nombre del emplazado, las partes del proceso, la naturaleza de éste o el juzgado que lo requiere, en un listado que se publica por una sola vez en un medio escrito de amplia circulación nacional o en cualquier otro medio masivo de comunicación. Este procedimiento se puede hacer en cualquier momento del proceso antes de la sentencia, pues ésta no se dictará mientras se encuentre pendiente el emplazamiento; así mismo, como requisito expreso del procedimiento laboral, el listado publicado debe también incluir la advertencia de habérsele designado curador.

De otra parte, cuando el demandado no es hallado o se impide su notificación, también procede el emplazamiento tal como se indicó anteriormente, sin embargo, teniendo en cuenta que el Código Procesal Laboral no establece la forma en la que debe realizarse la notificación, por analogía debe aplicarse lo dispuesto por el Código de Procedimiento Civil.

Ahora bien, en lo que respecta a la forma en que ha de realizarse la citación al demandado para que se efectúe la notificación personal, la norma no lo expresa, con lo cual se hace más que evidente el vacío jurídico que se presenta al respecto, y por lo cual debe recurrirse a lo establecido en el numeral 1 del artículo 29 de la Ley 794 de 2003, en este caso, si el demandado se hace presente en el Juzgado Laboral donde se ha iniciado el proceso se le notifica el auto admisorio de la demanda con el fin de hacer valer su derecho de defensa, pero en caso de que el citado no concurra, debe procederse de la misma manera, según lo dispone la normatividad procesal civil, practicándose la notificación por nombramiento de curador ad litem; o también se puede hacer mediante la notificación por aviso si la citación a la notificación personal fue recibida en el domicilio del demandado a pesar que el demandado no concurra al despacho. Una vez se ha cumplido con estas formalidades, se continuará con el proceso.

Analizada la normatividad en materia laboral en cuanto al trámite a seguirse para efectos de notificar al demandado el auto admisorio de la demanda, surgen claras divergencias frente al mismo trámite en materia civil, pues tal como ya se ha dicho, en el trámite ordinario laboral se procede al nombramiento del curador ad litem antes de que se efectúe el emplazamiento debido, mientras que en materia procesal 
civil primero ha de realizarse el emplazamiento para posteriormente, en caso de no lograrse la comparecencia del demandado para notificarse de dicha providencia, sí realizar el nombramiento del curador para la litis, lo que a primera vista se muestra como un trámite mucho más garantista frente al que se surte en la jurisdicción laboral.

La norma que regula el trámite atinente al nombramiento del curador ad litem en el Código de Procedimiento Civil es el ya mencionado artículo 318, que al respecto taxativamente enuncia:

“ (...)El emplazamiento se entenderá surtido transcurridos quince (15) días después de la publicación del listado. Si el emplazado no comparece se le designará curador ad litem, con quien se surtirá la notificación"

\section{Procesos civiles y ordinarios laborales}

De esta manera, es más que evidente el trato desigual que se da al demandado en un proceso ordinario laboral frente a uno civil, siempre que la norma procesal en materia laboral claramente da lugar a latentes trasgresiones a derechos y garantías con que se supone cuentan todos los sujetos procesales según lo establece la misma Constitución Nacional e incluso en instrumentos internacionales, pues al procederse al nombramiento de curador ad litem antes de que se efectúe el emplazamiento al demandado se ven menguadas principalmente las posibilidades de ejercer plenamente el derecho de defensa.

En este asunto, no sólo se ve comprometida la garantía del derecho a la defensa, sino además otros principios procesales como la publicidad, la contradicción, y la igualdad, que entran en disputa con otros tales como la economía procesal o la celeridad, toda vez que se presentan en diferentes escenarios amparando, ya sea al demandante o al demandado en un proceso judicial; sin embargo, cabe analizar cuáles de estos principios deben contar con mayor prevalencia frente a los otros al momento de pretenderse notificar una providencia tan importante como lo es el auto admisorio de la demanda en un proceso ordinario laboral.

De conformidad con el artículo 29 de la Constitución Nacional, toda persona tiene derecho a la defensa y a la asistencia de un abogado, garantía que también se encuentra consagrada en el artículo 3 de la ley 270 de 1996, que establece que en toda clase de actuación judicial y administrativa sin distinción, se garantiza el derecho a la defensa de acuerdo con la Constitución Política, los instrumentos internacionales ratificados por Colombia y la ley, además de deberse tener en cuenta que el derecho a la defensa encuentra íntima relación con la noción de debido proceso también protegida por el artículo constitucional ya citado.

El debido proceso como principio procesal y constitucional implica aquella sumatoria de garantías que protegen a quienes se someten a cualquier tipo de proceso y que les asegura una recta y cumplida administración de justicia, de donde a su vez se deriva el ya muy citado derecho a la defensa que pretende garantizar la salvaguarda de otros principios como el de contradicción de la prueba a fin de 
demostrar la inexistencia de los hechos o responsabilidades que se ha atribuido en su contra, en este caso a través de la demanda que ha dado lugar al inicio de un proceso judicial.

Podría pensarse que estos dos principios el debido proceso y la contradicción son plenamente garantizados a las partes intervinientes en una litis, sin embargo, no basta con la garantía que estos puedan tener si se dejan de lado otros tantos principios que de ninguna manera pueden ser desconocidos siendo que se encuentran incluso al mismo nivel, y sin los cuales la trasgresión de garantías a las partes se hace latente, tal y como se presenta en el asunto en comento.

El proceso judicial en sí implica gran cantidad de principios de orden constitucional y legal como son principios al debido proceso y a la defensa, publicidad, contradicción, inmediación, celeridad, economía procesal, igualdad, que deben ser plenamente garantizados a quienes intervienen en el desarrollo de los mismos sin importar la jurisdicción de que se trate.

A nivel de los trámites judiciales siempre se pondera el principio de igualdad que según la ley, e incluso la misma Constitución Política, debe regir el desarrollo de los mismos a fin de garantizar pleno equilibrio entre las partes intervinientes en la litis, sin embargo, en muchas ocasiones dicho principio, que se considera fundamental, se ve seriamente vulnerado a partir de las mismas disposiciones normativas que dan lugar a inclinar la balanza y las oportunidades hacia una de las partes, dando lugar así a la consecuente vulneración de muchas otras garantías que encuentran íntima relación con este principio, como es el caso de los derechos de contradicción y defensa que de igual manera son esenciales en el desarrollo de cualquier proceso judicial al permitir la práctica y controversia del material probatorio que finalmente permitirá el esclarecimiento del asunto que se debate, contando además con la adecuada asesoría por parte de quienes conocen la normatividad y brindan a través de esto la seguridad jurídica que amerita el proceso que se desarrolla

Junto a estos principios se encuentran otros que si bien se consideran de una menor categoría, no por esto dejan de ser vitales en la tramitación de los procesos judiciales al permitir el correcto desarrollo de los mismos, como se presenta en cuanto a los principios de economía procesal y publicidad que de la misma forma deben estar presentes, asegurando así la garantía de otros principios ya mencionados como los de defensa y contradicción, evidenciándose así la compleja interrelación que se presenta entre todos estos, en donde la trasgresión de tan sólo uno de ellos implica la vulneración de muchos otros .

Si se revisa la legislación procesal tanto civil como laboral, antes transcrita, que estipula lo correspondiente a los trámites de notificación del auto admisorio de la demanda en estos procesos, podría pensarse que cada una de ellas salvaguarda los principios y garantías procesales en pro de los intervinientes, sin embargo, si se detiene el análisis en el trámite establecido para tal fin, en los procesos ordinarios laborales se encuentra que el hecho de que la designación de curador ad litem se efectúe previo el emplazamiento al demandado, vulnera en gran medida las 
posibilidades de defensa con que puede contar quien resulta encartado en un proceso de este tipo.

Si bien con la figura del curador se pretende en un primer nivel permitir la adecuada defensa de los intereses de los demandados que no se presentan a conocer el asunto y ejercer su defensa por sí mismos, bien sea por fuerza mayor, o bien por negligencia de su parte, lo cierto es que en muchas ocasiones el proceder del curador termina por perjudicar los intereses de quien representa, pues el conocimiento de los hechos y las circunstancias reales que motivaron el inicio del proceso es mínimo frente a la información que maneja quien directamente se ve involucrado, con lo que es clara la vulneración tajante al principio de defensa y contradicción en contra del demandado, más aun en el caso en que se hace imposible su notificación por desconocimiento de su paradero o la imposibilidad de que esta se surta satisfactoriamente.

Una de las razones que podría explicar el trámite diferente, e incluso discriminatorio, que se presenta en los procesos ordinarios laborales para realizar la notificación del auto admisorio de la demanda frente al mismo trámite en los procesos civiles, en donde primero se realiza el emplazamiento al demandado y posteriormente en caso de ser procedente se designa curador ad litem, es la característica especialísima que se presenta en materia laboral referente a la impulsión oficiosa de los procesos, que resulta ser una prioridad en los procesos laborales, toda vez que lo que, se busca es que el proceso sea rápido y no existan ataduras para el demandante que lo único que busca es la defensa de sus derechos laborales.

En los asuntos laborales la impulsión oficiosa de los procesos se presenta de manera mucho más evidente que en otros trámites procesales, pues pese a que en principio el proceso laboral es eminentemente rogado para su iniciación, es obligación del juez impulsarlo por su propia iniciativa en aras de ponerlo en posibilidad de proferir la sentencia correspondiente que le ponga fin a la contención sometida a su conocimiento (Botero, 2004, 49). Esta característica, esto es, la impulsión oficiosa, encuentra fundamento en el principio de la protección al trabajador demandante, el cual ha contado con tratamiento jurisprudencial por parte de la Corte Suprema de Justicia que incluso ha indicado la facultad con que cuentan los juzgadores para dar aplicación a la norma que se presente más favorable a los intereses del trabajador y a la facultad de fallar extra y ultra petita en los procesos laborales (Corte Suprema de Justicia, Sala de Casación Laboral. Rad. 6630. M.P. Rafael Méndez. 1994).

Sin embargo, no puede darse relevancia únicamente a las garantías procesales hacia una de las partes, en el caso del procedimiento ordinario laboral hacia la parte demandante, máxime cuando se encuentra de por medio el ya muy citado principio de igualdad, básico en cualquier tipo de actuación judicial, y el cual no puede ser desconocido en ningún momento y menos aun de manera tan latente como se da en este caso.

La doctrina ha intentado sin éxito dar respuesta a la situación de divergencia que se presenta en los trámites de designación de curador ad litem en los procesos civiles 
y laborales, lo que pone de manifiesto la relevancia que toma el asunto desde la perspectiva procedimental, pues ante todo, como es bien sabido, se busca la garantía de aquellos principios y derechos base de los trámites procesales que ya han sido mencionados reiteradamente, y los cuales se ven seriamente trasgredidos con las disposiciones del Código Procesal Laboral.

Si bien, como se ha dicho, el procedimiento laboral establece pautas particulares que buscan el amparo y la protección de los trabajadores que deben acudir ante la administración de justicia para lograr el respeto y la garantía de sus derechos, no menos importantes resultan las garantías que de la misma manera se encuentran en cabeza de los empleadores que se ven involucrados en procesos judiciales, quienes en muchas oportunidades terminan completamente exonerados de todo tipo de responsabilidad frente a las pretensiones formuladas en su contra, para lo cual debieron recurrir al ejercicio del derecho a la defensa de que son acreedores, el cual ejercido a través de curador ad litem, muy seguramente no hubiera obtenido los mismos resultados.

\section{A manera de conclusión}

Así, la diferencia que se presenta entre los trámites en materia civil y materia laboral para la designación de curador ad litem evidencia una clara violación a las garantías procesales de los demandados en este tipo de pleitos judiciales, concretamente en lo que respecta al tema laboral, pues no puede pretenderse amparar únicamente a una de las partes desconociendo los derechos y garantía de la otra. Tal como se ha dejado expuesto en la normatividad que regula el asunto, existen grandes vacíos jurídicos que deben ser llenados a través de la aplicación, por analogía, de otras disposiciones; por lo que no se encuentra explicación para que en la práctica se presenten diferencias cuando en esencia se busca la obtención del fin último, que en materia jurídica es el esclarecimiento y la solución de los hechos partiendo de la aplicación de la ley.

La disputa que surge entonces entre la aplicación de unos principios y derechos frente a otros, abre el espacio para la disertación acerca de la prevalencia que algunos de estos pudieren tener en lo que respecta al trámite establecido en materia de los procesos ordinarios laborales; sin embargo, realizando un ejercicio comparativo es claro que con la norma procesal laboral vigente para la designación de curador ad litem, se trasgreden muchos más principios de los que eventualmente podrían resultar afectados si se aplicare el trámite que rige el procedimiento civil, es decir, la designación de curador ad litem una vez se haya surtido el debido emplazamiento al demandado, y no el emplazamiento luego de la designación del curador, como lo establece el procedimiento laboral.

La protección especial que ostenta el trabajador demandante frente al empleado demandado no puede ser superior a los derechos a la igualdad, la defensa, o el debido proceso que de igual manera se encuentran en cabeza del demandado, así como 
tampoco puede darse soporte a tal discriminación alegando la búsqueda de celeridad en las actuaciones judiciales, máxime cuando éste principio propende por el mínimo desgaste del aparato judicial, sin dejar de lado la búsqueda de la justicia.

De esta manera, la reforma al procedimiento de designación de curador ad litem en los procesos ordinarios laborales se hace completamente evidente para lograr la garantía de cada una de las partes intervinientes en una litis, y no únicamente inclinar la balanza hacia una de ellas, en este caso la parte demandante, que tal como se encuentra actualmente establecido cuenta con mayores garantías frente a la demandante, quien ve disminuida seriamente su posibilidad de ejercer el más básico de lo derechos que le asiste... la legítima defensa.

Teniendo en cuenta que los vacíos jurídicos que se presentan en cualquier materia procesal deben ser llenados a través de la remisión al procedimiento civil, no se encuentra razón alguna que explique el trato desigual que se da en el trámite en cuestión frente al tema laboral, más aun cuando en el mismo asunto se da aplicación a las disposiciones civiles en lo que hace a la manera de surtirse la notificación, por lo que se hace necesaria una reforma al procedimiento establecido para los procesos ordinarios laborales en aras de dar plena garantía a los principios procesales que, como se ha dicho anteriormente, son la esencia del trámite.

La designación del curador ad litem en los procesos ordinarios laborales requiere ser realizada de la misma manera en que se surte en los procesos civiles, es decir, procediendo en primera medida al emplazamiento del demandado para posteriormente si designarse al curador, eso sí, teniendo la tranquilidad de haberse protegido las garantías y los derechos de los encartados, pues de qué vale el amparo a los derechos de los empleados demandantes frente al desconocimiento de los derechos de los empleadores demandados, cuando lo que debe primar es el trato igualitario sin ningún tipo de diferencia buscando la salvaguarda de los derechos de ambas partes, más aún cuando se trata de la primera comunicación que se hace al demandado, cual es la notificación del auto admisorio de la demanda, que de por sí implica el primer paso para el ejercicio del fundamental derecho a la defensa, el cual no puede ser desconocido sobre la base de la protección a otros tantos derechos, que como se ha dejado en claro, pueden verse latentemente trasgredidos. 


\section{REFERENCIAS}

Botero, G. (2008). Guía Teórica y Práctica de Derecho Procesal del Trabajo y de la Seguridad Social. Bogotá.

Cabanellas de Torres, G. (2003). Diccionario Jurídico Elemental. Editorial Heliasta.

Código de Procedimiento Civil. Legis.

Constitución Política de Colombia. Legis.

Isaza, G. (1995). Practica Laboral. Primera Edición. Editorial LEYER. Bogotá.

López, H. (2005). Procedimiento Civil Tomo I. Dupré Editores. Bogotá.

Rodríguez, G. (1980). Curso De Derecho Procesal Laboral. Ediciones Librería Profesional. Segunda edición. Bogotá. 1980.

Vallejo, F. (2008). La Oralidad Laboral. Teoría-Práctica y Jurisprudencia. Jurídica Sánchez. Medellín.

(2004). Guía Teórica y Práctica del Derecho Procesal del Trabajo y de la Seguridad Social. Medellín: Ediciones Jurídicas Gustavo Ibáñez C. Ltda.

Villamil, E. (1999). Teoría Constitucional del Proceso. Ediciones Doctrina y Ley. Bogotá. 
